\title{
The Elephant That Didn't Get a Visa to Be in the Room
}

\author{
Helena Barnard, University of Pretoria, South Africa
}

IT WAS A WONDERFUL SURPRISE: Robert Grosse, immediate past president of AIB, wrote to ask if I would be one of two scholars from a lower income country to represent AIB at the upcoming World Investment Forum in Geneva. It was short notice, but they could support me. Could I make it? They were keen for the voices of people from outside the wealthy countries to be heard too.

I had hardly travelled abroad until I moved from South Africa to the US in 1998. But from the US, it was so fast to get to Europe-flights were typically five or six hours, rather than the twelve or more hours they took from South Africa. And there were so many of them, and so affordable! I spent time in Europe just about every summer during my PhD studies. Upon my return to South Africa my international travels did not stop: I travelled three and four times a year to conferences in my field. As a scholar of international business, I can see the arc of an abstract concept like "globalisation" in the pattern of my travels, but my most vivid association with those travels relates to applying for a visa.

I remember standing in the freezing cold for two hours in the visa queue outside the French embassy. I remember standing in a hardlyprivate cubicle trying to explain to a fairly aggressive interrogator that I really only wanted to attend a conference in Canada. A school friend who had immigrated to Belgium offered

to pay all expenses on my visit, but an experienced visa applicant advised me to make sure that I also showed some cash reserves. So I timed my visa application for the day after l'd received my stipend, and drew my bank statements on payday before paying my rent. I waited in anxious anticipation for the invitation letter (it had to be an original, mailed letter) to arrive. The wonder, of course, of advanced economies is that institutions like the postal service actually work: It was there in less than a week. The year my sister was helping Dole France to implement Sarbanes-Oxley, I went to visit her in Paris, but it turned out that you could only stay with and be supported by a person who was registered with the local municipality. My sister was there on a four month contract, and not registered. But she had a real job while I was living on a stipend, so she dumped the needed amount of cash into my account with the kind of hissing threat that only a sister can make to murder me if I even just thought about touching it. I booked a hotel and cancelled my booking the day after my visa was issued.
It was in the waiting room of the Italian consulate in Manhattan, listening to the accents and looking at the many hues of people around me that a fairly obvious realisation dawned on me: Citizens of rich countries do not need visas to visit other rich countries. There are visa waivers in place between almost all the high income countries. Visas exist, in practice if not in intent, primarily to govern the movements of citizens of poorer countries.

Things were no different once I got back to South Africa. I was involved with an EU FP7 grant to study the globalisation of innovation, but could not get a three year visa for the period that it was in effect. I applied for a Schengen visa four times, I think, during the life of the grant. On one occasion I remember showing up with an obscene bundle of cash (in those days, it was cash only, and visas are expensive when strong currencies are translated into emerging market currencies) and discovered that because the Rand had been weakening quite a bit that month, the amount that was posted on the web was less than the charged amount. Or my joy when I discovered that there was a processing centre for Danish visas in Johannesburg, and my frustration when I discovered that visas still had to go to Pretoria and that their internal processes were so slow that I would not get my visa done in time. And since they accepted applications only till $11 \mathrm{am}$, I had missed the

\section{(s) Visas exist, in practice if not in intent, primarily to govern the movements of citizens of poorer countries}

window of opportunity for that day, and had to cancel a meeting the next morning to go to Pretoria to get my application in on time. Where I discovered that I needed to obtain a police report to provide evidence that I did not have a crime record...

When the generous offer of the AIB came, I was concerned most of all with the risk and time involved in getting a visa, what Schotter and Beamish (2013) term the "hassle" factor. Here's what actually decided me: I have an 18-year old daughter who'd been working on a yacht in the Mediterranean the past few months. If I could visit her for a few days before the World Investment Forum, I'd be prepared to go through the schlep of applying for a visa. It took her only one hour to respond: It would be great if I could come, and I must please stay with them on the boat as there won't be guests at that time and then I can meet the 
captain and crew. An 18-year old who takes only one hour to respond to a message and seems keen to introduce her mother and her boss to each other... That reeks of homesickness. Of course I had to go.

Visa applications are by their nature tedious. I had to obtain proof that I was employed and that I would be returning to my employment. I had to get an official invite letter from AIB (PDF acceptable, I hoped, because the postal service in South Africa has spent most of the past two years either striking or catching up from a strike). I had to get bank statements of the past three months from AIB to show they could support me, which struck me as terribly intrusive. I decided that since I have a job and can support myself, I would instead show my own bank statements. And recent photos and travel insurance and flight information and accommodation information and a letter from WIF. And probably some other things I forget now, but there was a checklist and when I left to go to Pretoria to apply, I had everything that was needed. Truthfully, it made me feel a bit more confident that I was the invited guest of the AIB at an event run by a United Nations agency.

In recent years, consulates and embassies no longer interact directly with applicants for visas. Instead, there are processing centres that check all documentation and send through applications. They are bureaucrats who have no decision-making authority. They simply check that all rules are met and charge an additional amount of about 50\% of the visa fee. When I got to the processing centre, I was asked if I was there for a British, Australian or Swiss passport, and directed to the right place.

Here's what I had done wrong: Schengen visas must be issued by the country of first entry or the country of the longest stay. I was transiting via Germany, and spending four nights each in France and in Switzerland. But counting the hours, I was spending three hours more in France than in Switzerland. The Swiss would not process the application. The manager called the embassy when I protested, and came back confirming the instruction. I had to withdraw my visa application and apply from scratch at the processing centre that was handling French visas. He sympathetically said that I should rather book a hotel in France than rely on the by-then extensive email correspondence between my daughter and myself about staying on the boat; emails are not accepted.

The only reason why I did not pull out at that point was a dear 18-year old who was sending me Whatsapps with emoticons of sad faces and thumbs-ups and hearts and heartfelt wishes for a good outcome. So I went ahead and redid everything via the French embassy. I did what I had done when I was a doctoral student-booked a hotel to get a visa with no intent of staying there. In all, I spent about ten hours to get a visa for a trip of ten days.

The World Investment Forum was wonderful. The topics were truly geared to issues facing developing countries and so many of the attendees were really keen to hear the voices of people from developing countries. People like me. But structurally, there is a problem that did not make it into the room. The other delegate, Maria Alejandra Gonzalez Perez from Colombia happened to already have a visa, but her encouraging note is telling: "Let me know if I can support you with anything. Visa application is very stressful." The challenges and cost of getting a visa is what participants from poor countries discuss sympathetically amongst each other over coffee breaks; for the rest of the conference it seems to hardly exist.

I am baffled each time I apply for a visa to attend a conference and must choose between two options: tourism or business. A no-nonsense immigration officer once emphatically explained that conferences are tourism, and whenever I miss the early morning sessions at a conference because I was partying too hard the night before, I console myself that I am simply sticking to the terms of my visa. But surely the evidence of the benefits that accrue when there is a flow of information and free sharing of knowledge is solid enough for there to be a special dispensation for people who attend bone fide conferences and forums such as the World Investment Forum?

South Africa has thousands of illegal immigrants pouring into the country. I am very aware of the often ungenerous but very real political pressures that keep measures like visas for people from poorer countries in place. In fact, citizens from low income countries often find the visa offices of middle income countries particularly ungenerous. The IDRC (a Canadian grant agency doing extensive research on development) sponsors students from elsewhere in Africa to do their PhD at GIBS where I work. Last year a Nigerian and a Congolese student had to defer the start of their studies because of the unhelpful attitude of the respective South African visa authorities in their countries. And recently, one of GIBS'MBA students wanted to go on the global elective to Russia. As a Swazi national, his visa application required of him to undergo an HIV test.

In a globalising world, the cost and especially time required to get visas are becoming a tax on people from poorer countries. The fact that visas are so seldom discussed is probably an indicator that most of the conversation about opening business opportunities for emerging markets is about how to allow people and firms from wealthy countries access to those countries, rather than the reverse.

Of course, any business that wants to establish operations abroad has to meet numerous regulatory and legal requirements. But there is an exploratory phase where businesses try to find out if there is a basis for such investment. Visa requirements are the exact opposite of "exploratory" and a barrier for business people who need to explore options abroad. So South African entrepreneurs have a variety of strategies they use to overcome that barrier. Good immigration lawyers are a competitive advantage, as are parents or even grandparents with ancestry in a Triad country. I once met a manager who had applied for an EU passport on the basis that his great-grandparents had fled the pogroms of Lithuania. The programme apparently allowed for passports for the descendants of refugees, but only from something like 1898 onwards, and his great-grandparents had fled two years earlier. The historical evidence was understandably quite faded, and a bit of retouching could change the date. His big concern was how to find out if the system had a memory of his previous application. 
This incident makes me wonder whether visas can be categorised purely as a "hassle" factor: Is that the right term for inducing semi-legal behaviour in an honest and trustworthy manager or, for that matter, in a settled academic? After all, I am not sure that making a hotel booking that one plans to cancel is that much more or less honest than shifting the date of one's great-grandparents' flight from persecution. And is it pure "hassle" if Swazis (but not South Africans with an equally high HIV infection rate, but in the perhaps entirely incidental process of acquiring controversial nuclear technology from Russia) have to undergo HIV tests to go to Russia: Is there not some discriminatory measure at play?

Sustainability considerations around carbon emissions would suggest reduced international travel, but the forces of globalisation and the known benefits of face-to-face contact are in fact increasing it. At the moment, decisions about global travelling are made by individuals on the basis of their environmental conscience, but there is limited guidance. As with so many resources, citizens of less developed countries consume less air travel, which is a function not only of income levels, but also of visa requirements.

There is a global oversight body for intellectual property protection, even though countries have some leeway in how they apply those guidelines. Is there not an opportunity to have such a body where global travel (and as part of it, visa regulations) can be discussed and regulations agreed? For example, it should be possible to develop guidelines on carbon footprint to help people make an environmentally informed choice between rail or air travel in a region like Western Europe.

Given the progress that has been made around managing HIV, is it acceptable to require of people to do an HIV test as precondition for a visa? And what about other serious communicable diseases, such as Ebola? As the global spread of disease is becoming an increasing threat, a global oversight body to assess risk and recommend restraints or not on international travel could help ensure fair and responsible movement of people.

Additionally, the increasing use of processing centres for visas introduces all kinds of complications. They have de facto taken away the possibility for a visa applicant to engage directly with the decision-maker about the visa. The electronic application process of processing centres also does not allow processing without a fairly long window, 15 days in the French case. What about emergency visas? As mothers are wont to do, I many times imagined my daughter in some dire crisis. A friend in Europe offered to be on stand-by for such an eventuality, but surely in a global world, some guidelines for how to regulate humanitarian travel would be useful?

Maybe a body to regulate travel globally even exists, but as someone who will have filled a 60-page "maxi" passport with visas before it expires, its operations are not visible. Having just benefited from the very concerted efforts of agencies like UNCTAD and AIB to hear voices from developing countries, perhaps the most useful step will be to allow them easier access to where (still) most of the conversations about development are held.
Helena Barnard (barnardh@gibs.co.za) is the Director of Research at the Gordon Institute of Business Science (GIBS) at the University of Pretoria in South Africa. She received her PhD in Management from Rutgers University. Her research interests are in how knowledge (and with it technology, organizational practices, and innovation) moves from more to less developed countries. She focuses both on organizational mechanisms (notably emerging multinationals) and individual mechanisms, especially the diaspora and scientific collaborations. 